\title{
Intraurban Analysis of Domestic Solid Waste Disposal Methods in a Sub-Sahara African City
}

\author{
Oluwole Samuel Ojewale \\ Department of Urban and Regional Planning, Obafemi Awolowo University, Ile-Ife, Nigeria \\ Correspondence should be addressed to Oluwole Samuel Ojewale; samueloluwole09@gmail.com
}

Received 17 August 2014; Revised 10 November 2014; Accepted 23 November 2014; Published 18 December 2014

Academic Editor: Brajesh Dubey

Copyright ( 2014 Oluwole Samuel Ojewale. This is an open access article distributed under the Creative Commons Attribution License, which permits unrestricted use, distribution, and reproduction in any medium, provided the original work is properly cited.

\begin{abstract}
The study examined the influence of socioeconomic attributes of residents on domestic solid waste disposal methods in Lagos metropolis, Nigeria. Primary data for the study were obtained through questionnaire administered on residents in Eti-Osa, Ikeja, and Mushin Local Government Areas (LGAs) representing the low, medium, and high densities, respectively, into which the sixteen LGAs in Lagos metropolis were stratified. One out of every four wards in each LGA was selected for survey. From a total of 15,275 residential buildings in the ten wards, one out of every forty buildings (2.5\%) was selected using systematic random sampling where a household head was sampled. Information obtained includes the residential characteristics and the disposal methods. Enquiries into the socioeconomic attributes of the residents showed that $59.9 \%$ were high income earners and $76.6 \%$ had attained tertiary school education. This study concluded that six disposal methods were common in the study area. Furthermore, through multinomial logistic regression, the influence of socioeconomic characteristics of residents (density, income, age of respondents, educational status, and length of stay) on domestic solid waste disposal methods varied significantly in Lagos metropolis. The study established that most of the solid waste disposal methods utilized by residents in Lagos metropolis were not environment-friendly.
\end{abstract}

\section{Introduction}

The rapid urbanization experiencing in the cities of the world has accentuated for a plethora of environmental challenges within the different residential spheres. These problems include urban sprawl, decaying inner-city, inadequate housing, crime, and congestion, among others. Of pertinent attention is the problem associated with waste management that is taking unprecedented complex dimension in the cities of developing nations. From engineering to behavioral science, how waste can be properly managed has become a germane issue via several studies [1-4].

An elaborate definition of the term waste embraces all unwanted and economically unusable by-products or residuals at any given place and time and any other matter that is discarded into the environment $[5,6]$. This definition suggested that what constitutes waste must occur in such a volume, concentration, constituency, or manner as to cause a significant alteration in the environment. Thus, apart from waste being an unwanted substance that is discarded, the amount of it and the impact it makes on the environment also become important considerations in defining waste. Events of the late 20th and early 21st centuries indicate that waste, in whatever form or classification: solid, liquid, or toxic, has become a major consequence of modernization and economic development [7]. Notably, the solid form of waste is fast becoming a menace in both developed and developing nations $[8,9]$.

As observed by past study [10], in countries around the world, one major environmental problem that confronts municipal authorities is solid waste management. The study posited that city governments and dwellers are confronted by mounting problems regarding the solid waste generation. The observation is in tandem with the assertion of other studies $[11,12]$ that, in third World cities, between one-third and one-half of the solid wastes generated remain uncollected. In high-income countries, the issues associated with solid waste usually centre on the difficulties and high cost of disposing the large quantity of solid waste generated from different sources. Extant study [13] posited that of striking concern are the management problems associated with the solid waste emanating from domestic sources. 
The management of domestic solid waste is one of the huge challenges of the urban areas of all sizes. From megacities to the small towns, it is always in the top five of the most challenging problems for city managers [12]. Independent studies [14-16] noted that the disposal of domestic solid waste generated is particularly problematic in cities of developing countries. In this regard, Nigeria is not exempted as evidences abound that the problems associated with poor domestic solid waste disposal are daily realities in most Nigerian cities.

The disposal of solid waste is the ultimate stage in solid waste management system, influenced by factors such as characteristics of waste to be disposed, cost consideration, availability of disposal site, cost of labour, and technical implication of methods of disposal [17]. Past studies established that the disposal methods often utilized include the use of sanitary landfill, composting, incineration, and pyrolisis. These methods are commonly used in developed countries [18-20].

There are other solid waste disposal methods mainly employed in developing nations [17, 21-23]. These methods include the use of designated and incidental open spaces, dumping of waste into drain during and after rainfall, on river banks, beside road, and burning and burying. Others include the use of uncompleted building, vacant land, and collection by government refuse van, private waste managers, and cart pushers. These methods are considered both naive and dangerous, as they are environmentally unfriendly [2427]. Based on the above, the available methods of solid waste disposal are investigated in Lagos metropolis in this study.

Therefore, this study is different from the above empirical studies because it attempted to provide answer to these research questions: Is there any significant difference in the solid waste disposal methods utilized by residents within the residential neighborhoods of Lagos metropolis? To what extent can the socioeconomic attributes of residents influence their methods of solid waste disposal in Metropolitan Lagos? Successfully providing answers to these questions will be pivotal to suggesting feasible measures to address challenges associated with domestic solid waste disposal in Lagos metropolis, a city regarded as one of the fastest growing megacities in the world. Thus, the study aimed at examining the influence of socioeconomic attributes of residents on the choice of solid waste disposal methods utilized in Lagos metropolis, Nigeria. This is with a view to provide information that can enhance solid waste management.

\section{Materials and Method}

Lagos is situated within latitudes $6^{\circ} 23^{\prime} \mathrm{N}$ and $6^{\circ} 41^{\prime} \mathrm{N}$ and longitudes $2^{\circ} 42^{\prime} \mathrm{E}$ and $3^{\circ} 42^{\prime} \mathrm{E}$. The physical growth and development of Lagos are tied to its expanding economic and political roles, which aided by its rapid and explosive population growth has been phenomenal. The state has a population of 17 million with approximately $85 \%$ living in the city of Lagos making it one of the most urbanized regions in Nigeria. The population density of the state is about 4,193 persons per square $\mathrm{km}$. However, in the built-up areas of Metropolitan Lagos, the average density is over 20,000 persons per square $\mathrm{km}$. The rate of population growth is about
600,000 per annum, which is ten times faster than that of New York and Los Angeles [28].

Lagos metropolis is the economic and financial capital of Nigeria. With a total of $999.6 \mathrm{~km}^{2}$ in land area, the metropolis is made up of 16 Local Government Areas (LGAs) [29]. Eti-Osa LGA has the largest land area of $299.10 \mathrm{~km}^{2}$; the second and the third largest are Ojo and Alimosho LGAs with $182 \mathrm{~km}^{2}$ and $137.8 \mathrm{~km}^{2}$, respectively. The total population that made up the metropolis has the largest concentration at Alimosho LGA $(2,047,026)$ while the second and third in terms of population size are Ajeromi-Ifelodun LGA $(1,435,295)$ and Mushin LGA $(1,321,517)$ [30].

Data for this study were from primary and secondary sources. The primary data was sourced through questionnaire administration and actual measurement of household solid waste generated in the study area. Through multistage sampling technique, the 16 Local Government Areas (LGAs) within Lagos metropolis were stratified into low, medium, and high density areas. In this study, a LGA with a population of 20-10,000 persons $/ \mathrm{km}^{2}$ was regarded as low density, while medium and high density have 10,001-20,000 persons $/ \mathrm{km}^{2}$ and above 20,000 persons $/ \mathrm{km}^{2}$, respectively. Simple random sampling technique was used to select Eti-Osa, Ikeja, and Mushin areas from the low, medium, and high density areas, respectively. The three selected LGAs were further stratified into existing electoral wards as recognized by the Independent National Electoral Commission (INEC) [31].

Information obtained from INEC showed that there were fourteen electoral wards in Mushin LGA, while Ikeja and EtiOsa LGAs have ten (10) wards each. One out of every four (4) wards in each LGA was selected through simple random sampling without replacement. Thus, ten (10) political wards were surveyed. There were 15,275 residential buildings in the selected political wards, with 8996, 3780, and 2499 in the high, medium, and low densities, respectively. Systematic random sampling technique was adopted in selecting one out of every forty buildings (2.5\%).

Using this method, a total of 384 buildings were sampled with a household head targeted in each building for questionnaire administration. Information obtained from residents includes their socioeconomic attributes and methods of solid waste disposal.

\section{Results and Discussion}

The socioeconomic attributes of the residents were considered important for this study. The frequency as well as percentage distribution of the variables examined across the different residential densities is summarized in Table 1. Income of respondents is a strong determinant of the manner with which residents of any given community manage their solid waste. In this study, the income groups for household heads were based on the income classification adapted from past study using the Lagos State Civil Service minimum wage as the benchmark $[32,33]$. Therefore, household heads who earn $18,780-\$ 50,000$ were regarded as low income earners (LI), and $\$ 50,001-\$ 100,000$ were referred to as middle income earners (MI), while the high income earners 
TABLE 1: Socioeconomic characteristics of residents in the study area.

\begin{tabular}{|c|c|c|c|c|c|c|c|c|}
\hline \multirow{2}{*}{ Variables } & \multicolumn{2}{|c|}{ High } & \multicolumn{2}{|c|}{ Medium } & \multicolumn{2}{|c|}{ Low } & \multicolumn{2}{|c|}{ Total } \\
\hline & Freq. & $(\%)$ & Freq. & $(\%)$ & Freq. & $(\%)$ & Freq. & $(\%)$ \\
\hline \multicolumn{9}{|l|}{ Income classification } \\
\hline $\mathrm{N} 18,780-\mathrm{N} 50,000$ (LI) & 12 & 5.3 & 8 & 8.5 & - & - & 20 & 5.2 \\
\hline $\mathrm{N} 50,001-\mathrm{N} 100,000$ (MI) & 88 & 38.4 & 46 & 48.9 & - & - & 134 & 34.9 \\
\hline Above $¥ 100,000$ (HI) & 129 & 56.3 & 40 & 42.6 & 61 & 100 & 230 & 59.9 \\
\hline \multicolumn{9}{|l|}{ Age of residents } \\
\hline 19-30 years & 32 & 14.0 & 5 & 5.3 & 12 & 19.7 & 49 & 12.8 \\
\hline $31-55$ years & 167 & 72.9 & 69 & 73.4 & 35 & 57.4 & 271 & 70.6 \\
\hline 56 and above & 30 & 13.1 & 20 & 21.3 & 14 & 23.0 & 64 & 16.7 \\
\hline \multicolumn{9}{|l|}{ Educational status } \\
\hline Primary school & 1 & 0.4 & 4 & 4.2 & - & - & 5 & 1.3 \\
\hline Secondary school & 51 & 22.3 & 30 & 31.9 & 4 & 6.6 & 85 & 22.1 \\
\hline Tertiary school & 177 & 77.3 & 60 & 63.9 & 57 & 93.4 & 294 & 76.6 \\
\hline \multicolumn{9}{|l|}{ Length of stay } \\
\hline $1-10$ years & 149 & 65.0 & 67 & 71.3 & 47 & 77 & 263 & 68.5 \\
\hline $11-25$ years & 78 & 34.1 & 25 & 26.6 & 14 & 23.0 & 117 & 30.5 \\
\hline $26-40$ years & - & - & 2 & 2.1 & - & - & 2 & 0.5 \\
\hline Above 40 years & 2 & 0.9 & - & - & - & - & 2 & 0.5 \\
\hline
\end{tabular}

Note: Freq. means frequency.

(HI) earn above $\$ 100,000$. Low residential density had the largest proportion of respondents with high income. This group accounted for $100 \%$. Residents in the high and medium residential densities with high income were $56.3 \%$ and $42.3 \%$, respectively. Also, the analysis of the residents that were middle income earners was $48.9 \%$ and $38.4 \%$ in the medium and high densities, respectively. This study posited that $59.9 \%$ of the residents in Lagos metropolis were high income earners.

The age of the household headsin the identified residential densities of Lagos metropolis was grouped into three. These were 19-30 years (the youths), 31-55 years (the young adults), and 56 and above (the adults) $[34,35]$. This study established that $70.6 \%$ of respondents in Lagos metropolis were young adults. The youth and adult respondents accounted for $12.8 \%$ and $16.7 \%$, respectively. However, analysis of the age distribution of residents within the identified residential densities revealed that young adults were dominant in the three residential densities. This age group constituted $72.9 \%, 73.4 \%$, and $57.4 \%$, respectively in the high, medium, and low residential densities. Next in descending order were the adults. This group of respondents accounted for $13.1 \%, 21.3 \%$, and $23.0 \%$ in the high, medium, and low residential densities, respectively.

Information on the educational status of respondents in the study area indicated that $76.6 \%$ of the respondents had tertiary educational qualification, while $22.1 \%$ had secondary school qualification. However across the three residential densities, majority of the respondents in the high and medium densities had tertiary educational qualification. This accounted for $77.3 \%$ and $93.4 \%$. The highest proportion of respondents with secondary school qualification was $22.3 \%$ and $31.9 \%$ in the high and medium densities, respectively.
The number of years a respondent has been living in the area was also investigated. This is referred to as the length of stay. The number of years a household has been living in an area was therefore categorized into four: that is, 1-10 years, 11-25 years, 26-40 years, and above 40 years [33]. Enquiry into this socioeconomic attribute showed that $68.5 \%$ of the respondents had lived in their residential area for 1-10 years. However, analysis of the age distribution of residents within the identified residential densities revealed that $34.1 \%, 26.6 \%$, and $23 \%$ of the respondents had lived for 11-25 years in the high, medium, and low residential densities, respectively.

3.1. Analysis of Domestic Solid Waste Disposal Methods in the Study Area. As shown in Table 2, six major disposal methods were common in the study area. The use of accredited private sector participation (PSP) accounted for $25.9 \%$ of disposal methods in high, $26.1 \%$ in the medium, and $38.6 \%$ in the low density areas. Similarly, as a form of social service and environmental management initiative provided by the Lagos State Government, $16.2 \%, 10.5 \%$, and $27.2 \%$ of the residents in the high, medium, and low densities, respectively, indicated that they often disposed their solid waste in Lagos State Waste Management's (LAWMA) refuse facility. Despite the above findings, the study still established that indiscriminate waste disposal was prevalent in Lagos metropolis. This assertion is premised on the fact that $(21.9 \%, 21.1 \%$, and $22.7 \%)$ of the residents disposed solid waste on the road in the high, medium, and low densities, respectively: a proportion as high as $16.5 \%$ and $18 \%$ of the residents dumped waste in the drain during rainfall.

Burning as a form of disposal practice accounted for $8.4 \%$ and $11.5 \%$ in the high and medium densities, respectively. The dumping of waste on open space was a practice found 
TABLE 2: Solid waste disposal methods in the different residential densities.

\begin{tabular}{|c|c|c|c|c|c|c|c|c|}
\hline \multirow{2}{*}{ Disposal methods } & \multicolumn{2}{|c|}{ High } & \multicolumn{2}{|c|}{ Medium } & \multicolumn{2}{|c|}{ Low } & \multicolumn{2}{|c|}{ Total } \\
\hline & Freq. & $(\%)$ & Freq. & $(\%)$ & Freq. & $(\%)$ & Freq. & $(\%)$ \\
\hline Burning & 28 & 8.4 & 23 & 11.5 & - & - & 51 & 8.23 \\
\hline LAWMA $^{* *}$ refuse facilities & 54 & 16.2 & 21 & 10.5 & 24 & 27.2 & 99 & 15.9 \\
\hline Accredited PSP ${ }^{* * *}$ & 86 & 25.9 & 52 & 26.1 & 34 & 38.6 & 172 & 27.7 \\
\hline Sometimes on the road & 73 & 21.9 & 42 & 21.1 & 20 & 22.7 & 135 & 21.8 \\
\hline Dump in the drains during rainfall & 55 & 16.5 & 36 & 18.0 & - & - & 91 & 14.7 \\
\hline Nearby open space & 36 & 10.8 & 25 & 12.5 & 10 & 11.3 & 71 & 11.5 \\
\hline Total & 332 & 100 & 199 & 100 & 88 & 100 & $619^{*}$ & 100 \\
\hline
\end{tabular}

${ }^{*}$ This exceeded number of questionnaires administered because residents adopted more than one method of disposal.

** LAWMA means Lagos State Waste Management Agency.

*** PSP means private sector participation.

TABLE 3: Multinomial logistic regression model of association between solid waste disposal methods and socioeconomic characteristics of residents.

\begin{tabular}{|c|c|c|c|c|c|c|c|c|c|}
\hline \multirow{3}{*}{ Parameters } & \multicolumn{3}{|c|}{ Burning } & \multicolumn{3}{|c|}{ LAWMA refuse facilities } & \multicolumn{3}{|c|}{ Accredited PSP } \\
\hline & \multirow{2}{*}{$\operatorname{Exp}(\beta)$} & \multicolumn{2}{|c|}{$95 \%$ CI for $\operatorname{Exp}(\beta)$} & \multirow{2}{*}{$\operatorname{Exp}(\beta)$} & \multicolumn{2}{|c|}{$95 \%$ CI for $\operatorname{Exp}(\beta)$} & \multirow{2}{*}{$\operatorname{Exp}(\beta)$} & \multicolumn{2}{|c|}{$95 \%$ CI for $\operatorname{Exp}(\beta)$} \\
\hline & & Lower & Upper & & Lower & Upper & & Lower & Upper \\
\hline \multicolumn{10}{|l|}{ Residential densities } \\
\hline Low & 1.000 & - & - & 1.000 & - & - & 1.000 & - & - \\
\hline Medium & .000 & .000 & - & .666 & .356 & 1.246 & 1.707 & .910 & 3.202 \\
\hline High & .396 & .214 & .733 & .405 & .228 & .719 & 1.643 & .951 & 2.839 \\
\hline \multicolumn{10}{|l|}{ Income group } \\
\hline Low income & 1.000 & - & - & 1.000 & - & - & 1.000 & - & - \\
\hline Middle income & 2.616 & .922 & 7.423 & .745 & .335 & 1.659 & 2.693 & 1.181 & 6.140 \\
\hline High income & .727 & .386 & 1.366 & 2.320 & 1.248 & 4.312 & 1.037 & .576 & 1.866 \\
\hline \multicolumn{10}{|l|}{ Age group } \\
\hline 19-30 (youths) & 1.000 & - & - & 1.000 & - & - & 1.000 & - & - \\
\hline 31-55 (young adults) & .000 & .000 & - & .467 & .177 & 1.233 & .629 & .238 & 1.663 \\
\hline $56-65$ (adults) & 1.248 & .544 & 2.866 & .582 & .257 & .993 & 1.716 & .858 & 3.432 \\
\hline \multicolumn{10}{|l|}{ School educational status } \\
\hline Primary school education & 1.000 & - & - & 1.000 & - & - & 1.000 & - & - \\
\hline Secondary school education & .000 & .000 & - & .401 & .038 & 4.195 & 1.619 & .160 & 16.339 \\
\hline Tertiary school education & .606 & .278 & 1.317 & .505 & .257 & .993 & 1.522 & .794 & 2.917 \\
\hline \multicolumn{10}{|l|}{ Length of stay } \\
\hline $1-10$ years & 1.000 & - & - & 1.000 & - & - & 1.000 & - & - \\
\hline $11-25$ years & .000 & .000 & - & $1.650 E 9$ & .000 & - & .950 & .058 & 15.574 \\
\hline $26-40$ years & .000 & .000 & - & $1.120 E 9$ & .000 & - & 1.160 & .069 & 19.635 \\
\hline Model $\chi^{2}$ (-2log likelihood) & 34.713 & & & 49.883 & & & 49.638 & & \\
\hline$N$ & 51 & & & 99 & & & 172 & & \\
\hline
\end{tabular}

in all the three residential densities. It however accounted for $10.8 \%, 12.5 \%$, and $11.3 \%$ of all the disposal methods in the high, medium, and low residential densities, respectively. The disposal of waste on vacant plots of land was common in places where landholders were yet to develop such land. It can be deduced from Table 2 that dumping of waste in runoff water especially during the rainy season was a means of disposal which in the high and medium densities accounted for $16.5 \%$ and $18 \%$. This analysis confirmed that most of the solid waste disposal methods utilized by the resident in Lagos metropolis were not environment-friendly.
Based on the above, this study examined the influence of certain socioeconomic variables on the disposal methods employed by residents. This was determined through Multinomial Logistic Regression Analysis as shown on Tables 3 and 4. The statistical technique was employed because categorical variables were to be analyzed. Each of the solid waste disposal methods was selected as dependent variables. Five other sets of variables were the predictors. These are residential density, income group, age group, educational status, and length of stay. Fifteen categories were further derived from these variables: residential density was classified into "low" 
TABLE 4: Multinomial logistic regression model of association between solid waste disposal methods and socioeconomic characteristics of residents.

\begin{tabular}{|c|c|c|c|c|c|c|c|c|c|}
\hline \multirow{3}{*}{ Parameters } & \multirow{3}{*}{$\operatorname{Exp}(\beta)$} & \multirow{2}{*}{\multicolumn{2}{|c|}{$\begin{array}{l}\text { Roadside } \\
95 \% \text { CI for } \operatorname{Exp}(\beta)\end{array}$}} & \multicolumn{3}{|c|}{ Dumping in the drains } & \multicolumn{3}{|c|}{ Nearby open space } \\
\hline & & & & \multirow{2}{*}{$\operatorname{Exp}(\beta)$} & \multicolumn{2}{|c|}{ 95\% CI for $\operatorname{Exp}(\beta)$} & \multirow{2}{*}{$\operatorname{Exp}(\beta)$} & \multicolumn{2}{|c|}{$95 \% \mathrm{CI}$ for $\operatorname{Exp}(\beta)$} \\
\hline & & Lower & Upper & & Lower & Upper & & Lower & Upper \\
\hline \multicolumn{10}{|l|}{ Residential densities } \\
\hline Low & 1.000 & - & - & 1.000 & - & - & 1.000 & - & - \\
\hline Medium & .364 & .190 & .697 & .364 & .190 & .697 & .190 & .087 & .415 \\
\hline High & 3.670 & 2.029 & 6.637 & 3.670 & 2.029 & 6.637 & 1.086 & .639 & 1.845 \\
\hline \multicolumn{10}{|l|}{ Income group } \\
\hline Low income & 1.000 & - & - & 1.000 & - & - & 1.000 & - & - \\
\hline Middle income & .243 & .107 & .553 & .243 & .107 & .553 & .795 & .359 & 1.757 \\
\hline High income & .743 & .404 & 1.366 & .743 & .404 & 1.366 & .902 & .504 & 1.614 \\
\hline \multicolumn{10}{|l|}{ Age group } \\
\hline 19-30 (youths) & 1.000 & - & - & 1.000 & - & - & 1.000 & - & - \\
\hline 31-55 (young adults) & .543 & .196 & 1.505 & .543 & .196 & 1.505 & .225 & .076 & .665 \\
\hline 56-65 (adults) & .479 & .225 & 1.022 & .479 & .225 & 1.022 & .759 & .377 & 1.530 \\
\hline \multicolumn{10}{|l|}{ School educational status } \\
\hline Primary school education & 1.000 & - & - & 1.000 & - & - & 1.000 & - & - \\
\hline Secondary school education & 3.534 & .348 & 35.902 & 3.534 & .348 & 35.902 & 1.456 & .222 & 9.526 \\
\hline Tertiary school education & .478 & .242 & .944 & .478 & .242 & .944 & .584 & .302 & 1.132 \\
\hline \multicolumn{10}{|l|}{ Length of stay } \\
\hline $1-10$ years & 1.000 & - & - & 1.000 & - & - & 1.000 & - & - \\
\hline $11-25$ years & 1.322 & .081 & 21.685 & 1.322 & .081 & 21.685 & $1.825 E 9$ & .000 & - \\
\hline $26-40$ years & .716 & .042 & 12.190 & .716 & .042 & 12.190 & $2.036 E 9$ & .000 & - \\
\hline Model $\chi^{2}$ (-2log likelihood) & 49.341 & & & 36.350 & & & 47.450 & & \\
\hline$N$ & 135 & & & 91 & & & 71 & & \\
\hline
\end{tabular}

"medium" and "high"; income had three groups as well: "low," "medium," and "high," while the age group was divided into 19-30 (youths), 31-55 (young adults), and 56-65 (adults) [32]. Others were educational status of residents from which three categories were derived thus primary school education, secondary school education, and tertiary education, and lastly residents' length of stay was categorized into 1-10 years, 11-25 years, 26-40 years, and above 40 years [33]. Six major solid waste disposal methods were identified in Lagos metropolis. The summary of the Multinomial Logistic Regression Analysis on each of the disposal methods is thus presented.

Among the residents, the likelihood of burning as a disposal method was peculiar to all the categories of the independent variables. The model $\chi^{2}(-2 \log$ likelihood $)=34.713$ was significant at 0.001 confirming that there was a significant relationship between burning as a waste disposal method and the independent variables. Residents in the high density had an odd ratio of $.395 ; 2.616$ was associated with middle income category, and the adults with age range of 56-65 years and residents with secondary school education were 1.248 and .606 times more likely to utilize this disposal method.

The model fitting information of $\chi^{2}(-2 \log$ likelihood $)=$ 49.883, significant at 0.001 , established that a significant relationship also existed between the dependent and independent variables. Among the residents, the likelihood of using LAWMA refuse facilities as a disposal method waste was peculiar to all the categories of the independent variables. Residents in the medium density had an odd ratio of .666; 2.320 was associated with high income category, and the adults (56-65 years) and residents with tertiary education were .582 and .505 times more likely to utilize this receptacle, while residents who have lived for 26-40 years were 1.650 times more likely to utilize LAWMA facilities as a solid waste disposal method.

The model $\chi^{2}(-2 \log$ likelihood $)=49.638$, significant at 0.001 , established that a significant relationship existed between the dependent and independent variables. The likelihood of using accredited PSP as a disposal method was peculiar to all the categories of the independent variables. Residents in the medium density had an odd ratio of 1.707; 2.693 was associated with middle income category, and the adults (56-65 years) and residents with secondary school education were 1.716 and 1.619 times more likely to use this receptacle, while residents who have lived for 26-40 years were 1.160 times more likely to make use of this receptacle.

Among the residents, the likelihood of dumping solid waste on the roadside as a disposal method was peculiar to all the categories of the independent variables. The model $\chi^{2}(-2 \log$ likelihood $)=49.341$ was significant at 0.001 confirming that there was a significant relationship between the dependent variable and the independent variables. Residents 
in the high density had an odd ratio of $3.670 ; .743$ was associated with high income category, and the adults with age range of 31-55 years and residents with secondary school education were .543 and 3.534 times more likely to use this disposal method, while residents who have lived for 11-25 years were 1.322 times more likely to make use of this disposal method.

The model $\chi^{2}$ (-2log likelihood) $=49.341$, significant at 0.001 , established that a significant relationship existed between the dependent and independent variables. The likelihood of dumping household solid waste in the drains as a disposal method was peculiar to all the categories of the independent variables. Residents in the high density had an odd ratio of $3.670 ; .743$ was associated with high income category, and the young adults (31-55 years) and residents with secondary school education were .543 and 3.534 times more likely to resort to this adverse disposal method, while residents who have lived for 11-25 years were 1.322 times more likely to make use of this receptacle.

The model fitting information of $\chi^{2}(-2 \log$ likelihood $)=$ 47.450, significant at 0.001 , established that residents in the high density had an odd ratio of 1.086; .795 was associated with high income category, and the adults (56-65 years) and residents with secondary school education were .759 and 1.456 times more likely to resort to this deleterious disposal method of dumping in nearby open space, while residents who have lived for 26-40 years were 2.036 times more likely to make use of this disposal method. It could be concluded from the foregoing that significant relationship existed between the solid waste disposal methods and with the socioeconomic of residents in Lagos metropolis. The study further posited that most of solid waste disposal methods utilized in Lagos metropolis were not environmentfriendly. This was confirmed by $56.2 \%$ of the respondents.

\section{Conclusions}

This study concluded that six major disposal methods were common in the study area. Furthermore, the influence of socioeconomic characteristics of residents (density, income, age, educational status, and length of stay) on domestic solid waste disposal methods varied significantly in Lagos metropolis.

Consequently, this study suggests a consistent public enlightenment and environmental sensitization for all citizens. This type of education should present the benefits and dangers attached to making the environment clean and otherwise. It should also be an avenue through which residents would be educated on their roles in achieving a clean and healthy living environment through healthy solid waste disposal methods. National Orientation Agency (NOA), government agency such as Lagos State Waste Management Agency (LAWMA), Lagos State Ministry of Environment, Federal Ministry of Environment, and Local Government Authorities can also collaborate with other nongovernmental organization and citizen group, such as Citizen Advisory Group [17], to develop modalities for informed environmental sensitization. Such enlightenment initiatives become highly imperative as majority of the respondents in the study area confirmed that significant proportion of solid waste disposal methods utilized in Lagos metropolis were not environment-friendly.

\section{Conflict of Interests}

The research being reported in this paper emanated from Effect of Residential Characteristics on Household Solid Waste and Street Litter Management in Lagos Metropolis, Nigeria, a M.Sc. degree thesis, submitted by the authorOluwole Samuel Ojewale-to the Department of Urban and Regional Planning, Obafemi Awolowo University, Ile-Ife, Nigeria, on 17th of July, 2014. The terms of this arrangement have been reviewed and approved by the Board of Examiner, Obafemi Awolowo University, Ile-Ife, Nigeria, on 4th of August, in accordance with its policy on objectivity in research.

\section{References}

[1] A. O. Afon, "Informal sector initiative in the primary subsystem of urban solid waste management in Lagos, Nigeria," Habitat International, vol. 31, no. 2, pp. 193-204, 2007.

[2] H. A. Arafat, I. A. Al-Khatib, R. Daoud, and H. Shwahneh, "Influence of socio-economic factors on street litter generation in the Middle East: effects of education level, age, and type of residence," Waste Management \& Research, vol. 25, no. 4, pp. 363-370, 2007.

[3] F. Contreras, S. Ishii, T. Aramaki, K. Hanaki, and S. Connors, "Drivers in current and future municipal solid waste management systems: cases in Yokohama and Boston," Waste Management and Research, vol. 28, no. 1, pp. 76-93, 2010.

[4] A. M. Kayode and F. K. Omole, "Some socio-economic factors affecting solid waste generation and disposal in Ibadan metropolis, Nigeria," Journal of Environmental Issues and Agriculture in Developing Countries, vol. 3, no. 1, 2011.

[5] A. Gilpin, Dictionary of Environment and Development, John Wiley \& Sons, Chichester, UK, 1996.

[6] O. Oresanya, "Waste control measures and responsibility of a waste manager within the framework of recent management methods and development in municipal and industrial wastes," in Proceedings of the Workshop on Effective Waste Management in Nigeria, The Nigerian Society of Engineers, Lagos, Nigeria, April 1998.

[7] I. A. Tsiboe and E. Marbell, A look at Urban waste disposal problem in Accra, Ghana [Masters thesis], Roskilde University, Roskilde, Denmark, 2004, http://www.ruc.dk/en.research.

[8] F. Contreras, S. Ishii, T. Aramaki, K. Hanaki, and S. Connors, "Drivers in current and future municipal solid waste management systems: cases in Yokohama and Boston," Waste Management \& Research, vol. 28, no. 1, pp. 76-93, 2009.

[9] D. Musademba, S. Musiyandaka, A. Muzinda, B. Nhemachena, and D. Jambwal, "Municipal solid waste (MSW) management challenges of Chinhoyi town in Zimbabwe: opportunities of waste reduction and recycling," Journal of Sustainable Development in Africa, vol. 13, no. 2, 2011.

[10] Asian Productivity Organization, "Solid waste management: issues and challenges in Asia," Report of the APO Survey on Solid-Waste Management 2004-05, Environmental Management Centre, Mumbai, India, 2007. 
[11] J. Post and N. Obirih-Opareh, "Partnerships and the public interest: assessing the performance of public-private collaboration in solid waste collection in Accra," Space and Polity, vol. 7, no. 1, pp. 45-63, 2003.

[12] UN-HABITAT, Collection of Municipal Solid Waste in Developing Countries, 2010.

[13] M. U. Nwachukwu, "Solid waste generation and disposal in a Nigerian city: an empirical analysis in Onitsha Metropolis," Journal of Environmental Management and Safety, vol. 1, no. 1, pp. 180-191, 2009.

[14] R. Girling, Rubbish! Dirt on Our Hands and Crisis Ahead, Eden Project Books, Transworld Publishers, London, UK, 2005.

[15] UNHABITAT and ECA-CEA, "The state of African cities: a framework for addressing urban challenges in Africa," HS/1036/08 E, 2008.

[16] D. Awunyo-Vitor, I. Shaibu, and G. S. Jasaw, Urban Households' Willingness to Pay for Improved Solid Waste Disposal Services in Kumasi Metropolis, Ghana, Department of Agricultural Economics, Kwame Nkrumah University of Science and Technology, Kumasi, Ghana, 2010.

[17] A. O. Afon, Solid waste management in selected cities of Oyo State [Ph.D. dissertation], Department of Urban and Regional Planning, Obafemi Awolowo University, Ile-Ife, Nigeria, 2005.

[18] M. A. Nwachukwu, H. Feng, and J. Alinnor, "Assessment of heavy metal pollution in soil and their implications within and around mechanic villages," International Journal of Environmental Science and Technology, vol. 7, no. 2, pp. 347-358, 2010.

[19] M. Alhassan and J. Mohammed, "Households' demand for better solid waste disposal services: case study of four communities in the new Juaben Municipality, Ghana," Journal of Sustainable Development, vol. 6, no. 11, 2013.

[20] M. Kumar and N. Nandini, "Community attitude, perception and willingness towards solid waste management in Bangalore city, Karnataka, India," International Journal of Environmental Sciences, vol. 4, no. 1, 2013.

[21] A. O. Afon, "Intra-urban differentials in solid waste disposal practice in Ogbomoso, Nigeria: implication for environmental education," Nigerian Journal of Construction Technology Management, vol. 9, no. 1, pp. 1-17, 2008.

[22] O. I. Nwachukwu, N. I. Chidi, and K. O. Charles, "Issues of roadside disposal habit of municipal solid waste, environmental impacts and implementation of sound management practices in developing country 'Nigeria,' International Journal of Environmental Science and Development, vol. 1, no. 5, pp. 409-418, 2010.

[23] K. S. Njoroge, M. S. Wokabi, K. Ngetich, and N. M. Kathuri, "Influence of informal solid waste management on livelihoods of urban solid waste collectors: a case study of Nakuru Municipality, Kenya," International Journal of Humanities and Social Science, vol. 3, no. 13, 2013.

[24] P. Rushbrook and M. Pugh, "Solid Waste Landfills in middle and lower income countries. A technical guide to planning, design and preparation," World Bank Technical Paper 425, Washington, DC, USA, 1999.

[25] K. A. Ayuba, L. A. Manaf, A. H. Sabrina, and S. W. N. Azmin, "Application of an integrative approach for municipal solid waste management assessment: towards adopting a conceptual model for efficient and sustainable solid waste management," Journal of Environment and Earth Science, vol. 3, no. 7, 2013.

[26] S. Mohapatra, “Technological options for treatment of municipal solid waste of Delhi," International Journal of Renewable Energy Research, vol. 3, no. 3, pp. 682-687, 2013.
[27] K. Vasanta and Priyasauni, "Sustainable municipal solid waste management strategies: need of PPP model for agra," Asia Pacific Journal of Marketing \& Management Review, vol. 2, no. 5, 2013.

[28] Canadian International Development Agency, Towards a Lagos State Climate Change Adaptation Strategy, Building Nigeria's Response to Climate Change (BNRCC) Project, Commissioner of Environment, Lagos State, Nigeria, 2012.

[29] K. A. Aderogba, M. Oredipe, S. Oderinde, and T. Afelumo, "Challenges of poor drainage systems and floods in Lagos Metropolis, Nigeria," International Journal of Social Sciences and Education, vol. 2, no. 3, 2012.

[30] Lagos State Government Digest of Statistics, Issued by: Lagos bureau of statistics Ministry of Economic Planning and Budget The secretariat Alausa, Ikeja, Lagos, Nigeria, 2011.

[31] Independent National Electoral Commission, Report on the 2011 General Elections, Independent National Electoral Commission (INEC), 2011.

[32] C. Ezeah, Analysis of barriers and success factors affecting the adoption of sustainable management of Municipal Solid Waste in Abuja, Nigeria [Ph.D. thesis], University of Wolverhampton, 2010, http://core.kmi.open.ac.uk/download/pdf/1933162.pdf.

[33] G. B. Faniran, Residents' perception of the monthly environmental sanitation exercise in Ibadan Metropolis, Nigeria [M.Sc. thesis], Department of Urban and Regional Planning, Obafemi Awolowo University, Ile-Ife, Nigeria, 2012.

[34] Vanguard Newspaper, Lagos Ratifies New Salary Package, 2011.

[35] World Health Organization, WHO Library Cataloguing-inPublication Data, World Health Organization, 2011. 

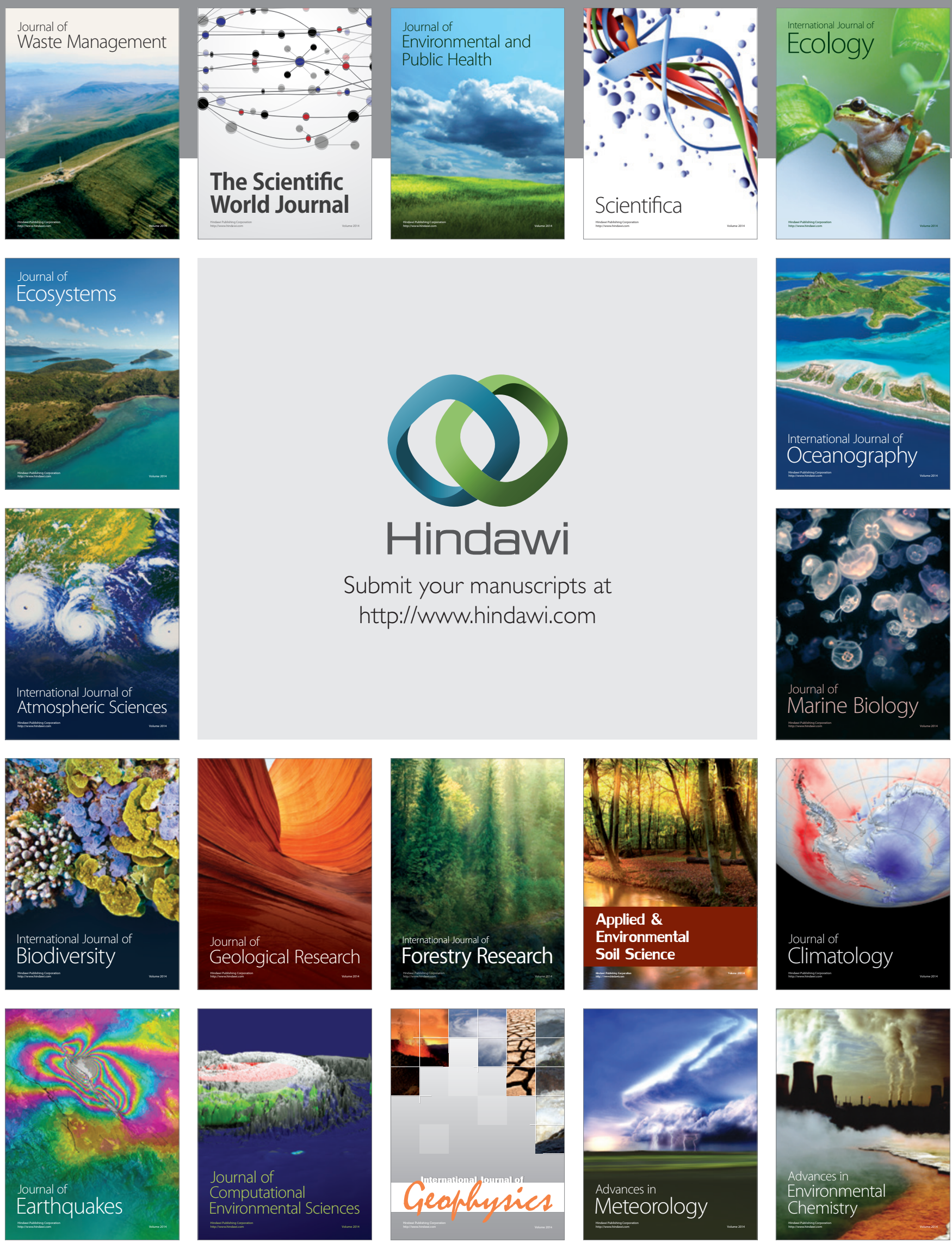